\title{
Immunological and Clinical Impact of Cancer Stem Cells in Vulvar Cancer: Role of CD133/CD24/ABCG2-Expressing Cells
}

\author{
CHIARA NAPOLETANO ${ }^{*}$, FILIPPO BELLATI ${ }^{1,2^{*}}$, ILARY RUSCITO ${ }^{1,3}$, MILENA PERNICE $^{3}$, \\ ILARIA GRAZIA ZIZZARI ${ }^{1}$, SALVATORE CAPONNETTO ${ }^{1}$, FEDERICA TOMAO $^{3}$, \\ LUIGI FRIGERIO $^{4}$, MARCO LIBERATI ${ }^{5}$, AURELIA RUGHETTI ${ }^{1}$, DONATELLA CASERTA ${ }^{2}$, \\ PIERLUIGI BENEDETTI PANICI ${ }^{3}$ and MARIANNA NUTI ${ }^{1}$ \\ Departments of ${ }^{1}$ Experimental Medicine, and ${ }^{3}$ Gynecology, \\ Obstetrics and Urology, Sapienza University of Rome, Rome, Italy; \\ ${ }^{2}$ Department of Medical and Surgical Sciences and Translational Medicine, \\ Sapienza University of Rome, Sant'Andrea Hospital, Rome, Italy; \\ ${ }^{4}$ Department of Gynaecology and Obstetrics, Papa Giovanni XXIII Hospital, Bergamo, Italy; \\ ${ }^{5}$ Obstetrics and Gynaecology Unit, SS. Annunziata Hospital Chieti, \\ G. d'Annunzio University Chieti-Pescara, Chieti, Italy
}

\begin{abstract}
Background: Cancer stem cells (CSCs) are tumour-initiating cells with self-renewal properties and chemo/radio-resistance. Regulatory T-cells (Tregs) influence CSCs through several mechanisms. In different solid tumours, the presence of both cell populations correlated with poor survival. In vulvar cancer, little is known regarding biological markers able to predict patient prognosis. We investigated the presence and clinical impact of CSCs and infiltrating Treg in primary vulvar cancer. Materials and Methods: Paraffinembedded tissue specimens derived from 43 patients with vulvar cancer were analyzed by immunohistochemistry for the expression of prominin-1 (CD133), CD24, ATP-binding cassette sub-family $G$ member 2 (ABCG2) (CSC markers) and forkhead box protein P3 (FOXP3) (Treg marker). Results: $C D 133$ expression correlated with younger age at diagnosis $(p<0.01)$, lymph-node metastasis $(p<0.05)$ and larger tumour diameter $(p<0.05) . \mathrm{CD}_{133^{+}}$tumours showed a high FOXP3 ${ }^{+}$ $T$-cell infiltration. Overall survival and progression-free survival were not influenced by the expression of the analyzed
\end{abstract}

This article is freely accessible online.

*These Authors contributed equally to this study.

Correspondence to: Filippo Bellati, MD, Department of Medical and Surgical Sciences and Translational Medicine, Sapienza University of Rome, Sant'Andrea Hospital, Via di Grottarossa 1035/1039, 00189, Rome, Italy. Tel/Fax: +39 063375479, e-mail: filippo.bellati@uniroma1.it

Key Words: Vulvar cancer, cancer stem cells, CD133, CD24, ABCG2. biomarkers. Conclusion: In vulvar cancer, CSCs were more frequently expressed in younger aged patients and those with aggressive disease. Their presence was also associated with high Treg infiltration, which contributes to the generation of an immunosuppressive milieu.

Vulvar cancer is an uncommon gynaecological malignancy; approximately 4,850 new cases of vulvar cancer and 1,030 deaths from this disease were projected for the United States in 2014 (1). Most patients are elderly, with a peak of incidence in the eighth decade; nearly $30 \%$ are diagnosed at international Federation of Gynaecology and Obstetrics (FIGO) stage III or IV with a 5-year overall survival of $43 \%$ and $13 \%$, respectively (2). Although representing a rare disease of elderly women with a current incidence of 2-3 per 100,000 women and a median age of 65-70 years old, vulvar cancer has shown an increasing incidence with concurrently decreasing median age of 55-60 years at onset over the past few decades $(1,3)$.

The standard treatment of vulvar cancer includes radical surgery and adjuvant radiotherapy in selected cases. Considering the median age of these patients, clinical and pathological prognostic factors are constantly being explored in order to minimize unnecessary treatments. Furthermore, new molecules are being investigated to propose target therapies and increase patient survival.

In the past decade, cancer stem cells (CSCs) have been identified as tumour-initiating cells. This subpopulation is resistant to cancer therapy such as chemo- and radiotherapies and successful treatments are dependent on the elimination of these cells (4). In addition, several reports highlight the interaction between CSCs and the immune system. 
Regulatory T-cells (Tregs) influence the stemness, progress and control of CSCs through regulating angiogenesis influenced by vascular endothelial growth factor (VEGF) (5, 6). CSCs impact on Tregs mainly through their recruitment and induction (7).

Prominin-1 (CD133) and forkhead box protein P3 (FOXP3) represent well-established markers of CSC and Tregs, respectively. Prominin-1 (CD133) is associated with tumour progression. Its up-regulation in tumours correlated with poor prognosis, although its function is unknown (8). FOXP3 is the master regulator of Tregs and it is essential for Treg development and function (9). In recent years, the CD24 and ATP-binding cassette transporter G2 (ABCG2) molecules have also been proposed as additional CSC markers for several solid tumour types (10). CD24 is a glycoprotein preferentially expressed by B-lymphocytes, that positively regulates the proliferation of activated T-cells, and it is also described in the central nervous system. Several studies conducted on colorectal cancer demonstrated that this molecule is associated with a poor prognosis and more aggressive phenotype of tumour cells (11). ABCG2 causes decreased drug concentration within the cells by pumping chemotherapeutic drugs out of the cell (12). In addition, it is implicated in the survival of stem cells and tumour cells in an hypoxic environment (13). In cancer, ABCG2 is associated with a poor prognosis and is often highly up-regulated in the small stem-like cell subpopulation (14).

In this work, we analyzed the expression of CD133, FOXP3, ABCG2 and CD24 in women affected by vulvar cancer, correlating these with common clinical prognostic factors.

\section{Materials and Methods}

Patient characteristics. This retrospective multi-institutional study included patients affected by vulvar cancer and treated between 1999 and 2010 in the following Italian Gynaecologic Oncology Units: Sapienza University of Rome, University of Chieti, Hospital of Bergamo. The Internal Review Boards of the involved Institutions granted approval for this study (protocol number 703/08). Data, including age, histopathology, tumour grading, lymph node involvement and treatment protocol, were obtained from clinical charts and pathological records. Follow-up was closed in March 2014.

Paraffin-embedded samples were obtained from patients affected by primary vulvar cancer and treated with radical surgery. Surgical procedures were carried out with the triple-incision technique. Patients with lesions involving only the vulva were subjected to radical vulvectomy or wide local excision in the attempt to obtain at least a $1 \mathrm{~cm}$ tumour-free resection margin. In cases of lower urethral involvement, a partial distal urethrectomy was performed. Superficial and deep groin lymph nodes were removed in cases of suspected metastatic involvement for optimal surgical staging. Patients with multiple lymph node metastases were treated with adjuvant radiotherapy.
Immunohistochemistry. Serial formalin-fixed, paraffin-embedded vulvar tumour samples were deparaffinised in xylene, followed by absolute ethanol, 95\% ethanol and distilled water. Before immunostaining procedures, sections were incubated in citrate buffer $\left(\mathrm{pH}\right.$ 6.0) or in EDTA buffer $(\mathrm{pH} 8.0)$ in a pressure cooker at $112^{\circ} \mathrm{C}$ to enhance immunoreactivity of samples. Endogenous peroxidase activity was quenched by treatment with $3 \% \mathrm{H}_{2} \mathrm{O}_{2}$. After blocking of the nonspecific sites, the sections were incubated with the following mouse monoclonal antibodies: anti-CD133/1 (AC133 clone, dilution 1:50, overnight at $4^{\circ} \mathrm{C}$; Miltenyi Biotech, Bergisch Gladbach, Germany), anti-CD24 (ready to use, $1 \mathrm{~h}$ at room temperature; Biocare Medical, Concord, CA, USA), anti-ABCG2 (6D171 clone, dilution 1:100 overnight at $4^{\circ} \mathrm{C}$; Santa Cruz, Heidelberg, Germany), anti-CD3 (PS1 clone, ready to use, $2 \mathrm{~h}$ at room temperature; UCS Diagnostic, Morlupo, Italy) and anti-FOXP3 (MCA2376 clone, 1:200, 1.5 h at room temperature; AbDSerotec, Kidlington, UK). Markers were visualized using the DakoEnVision + System Horseradish peroxidise (HRP)-labelled polymer kit (Dako, Santa Clara, CA, USA) following the manufacturer's instructions and the tissue sections were counterstained with haematoxylin (ScyTek Laboratories, West Logan, UT, USA).

The images were acquired with Olympus BX51 microscope (Olympus Europe SE \& Co. KG, Hamburg, Germany) and analyzed with IAS software (Rehlingen-Siersburg, Germany). Staining was graded according to the number of positive tumour cells as follows: $<5 \%$, negative; $>5-20 \%$, weak; $>20-50 \%$, moderate; $>50 \%$, strong. Negative control slides were incubated with MOC21 monoclonal antibody (AbCam, Cambridge, UK) as isotype control. Three independent investigators blinded to the patient clinical information evaluated all specimens.

The expression of each marker was evaluated using a $\times 20$ objective selecting 10 independent areas. In particular for the quantification of the CD3 and Treg markers, 10 areas with the most abundant tumour-infiltrating lymphocytes were selected, digitally photographed at a size of $0.0625 \mathrm{~mm}^{2}$, and counted manually. The count was performed three times for each photograph by the same investigator (E.S.) without knowledge of earlier results.

Statistical analysis. Statistical analyses were performed with the Fisher's exact test. Survival curves were plotted by means of Kaplan-Meier method and compared by using the log-rank test. A $p$-value (two-tailed) lower than 0.05 was considered significant.

\section{Results}

Patient characteristics. Forty-three patients were included. Patients' characteristics are listed in Table I. Briefly, the median age at diagnosis was 71 years. Most of the patients were affected by FIGO II (49\%) or III (42\%) stage tumours. Monolateral or bilateral inguinal lymphadenectomy for optimal surgical staging was performed in $93 \%$ (40/43) of cases.

CD133, ABCG2 and CD24 expression. Forty-three patients were evaluated for the expression of CD133, concurrently tumours from 31 women were also analyzed for the expression of ABCG2 and CD24.

In 43 patients examined, 11 samples were positive for the expression of CD133. This marker was weakly and 
Table I. Patient characteristics.

\begin{tabular}{lcc}
\hline Characteristic & No. patients & $(\%)$ \\
\hline Total & 43 & \\
Median age (range), years & $71(48-94)$ & \\
Grading & 6 & 14 \\
G1 & 26 & 60 \\
G2 & 11 & 26 \\
G3 & 4 & \\
FIGO stage & 21 & 9 \\
I & 18 & 49 \\
II & & \\
III & 2 & 5 \\
Surgical technique & 1 & 2 \\
Hemivulvectomy & 4 & 9 \\
Velvectomy & 20 & 47 \\
Hemivulvectomy + ML/BL & 15 & 37 \\
Vulvectomy + ML/BL & $3.2(0.3-6)$ & \\
Radical vulvectomy + ML/BL & \\
Median tumor diameter (range), cm & & \\
\hline
\end{tabular}

ML: Monolateral inguinal lymphadenectomy; BL: bilateral inguinal lymphadenectomy.

moderately expressed in eight (18.6\%) and three (7\%) samples, respectively, while no case showed strong CD133 expression (Table II).

In the 31 patients analyzed, $\mathrm{ABCG} 2^{+}$and $\mathrm{CD} 24^{+}$expressing cells were found in $90.3 \%$ (28/31) and $54.8 \%$ (17/31) of patients, respectively. ABCG2 was weakly expressed in $64.5 \%$ of samples, while $26 \%$ of women had a moderate or strong expression of this marker. CD24 presented a weak expression in 12 women (39\%), while four $(13 \%)$ and one (3.2\%) case showed moderate and strong expression, respectively. Three $(9.6 \%)$ and $14(45 \%)$ samples out of 31 were completely negative for the presence of ABCG2 and CD24, respectively. Figure 1 presents an example of the antigen distribution observed.

The expression of the three markers examined on 31 patients revealed that $16 \%(5 / 31)$ of the tumours expressed all three antigens, while only one sample (3.2\%) was completely negative.

No samples were $\mathrm{CD} 133^{+} \mathrm{ABCG} 2^{-} \mathrm{CD} 24^{+}$, while $3 / 31$ patients $(9.6 \%)$ were $\mathrm{CD} 133^{+} \mathrm{ABCG} 2^{+} \mathrm{CD} 24^{-}$. Eleven out of 31 patients $(35.5 \%)$ were $\mathrm{CD} 133^{-} \mathrm{ABCG} 2^{+} \mathrm{CD} 24^{+}$. Results are summarized in Figure 2.

Clinicopathological parameters and CD133, ABCG2 and $C D 24$ expression. Correlation between clinical parameters and tumour stem cell markers are reported in Table III. CD133 ${ }^{+}$ tumours were more frequently encountered in patients with lymph nodal metastasis $(p=0.03)$, larger tumour diameter $(p=0.03)$ and younger age at diagnosis $(p=0.001)$ respect to CD133- tumours. ABCG2 and CD24 were not significant correlated with commonly identified prognostic factors.
Table II. Intensity distribution of expression of cancer stem cell markers.

\begin{tabular}{lccc}
\hline Staining intensity & CD133+/total & ABCG2+/total & CD24+/total \\
\hline Negative $(<5 \%)$ & $32 / 43$ & $3 / 31$ & $14 / 31$ \\
Weak (5-20\%) & $8 / 43$ & $20 / 31$ & $12 / 31$ \\
Moderate (>20-50\%) & $3 / 43$ & $6 / 31$ & $4 / 31$ \\
Strong (>50\%) & $0 / 43$ & $2 / 31$ & $1 / 31$ \\
\hline
\end{tabular}

CD133: Prominin-1; ABCG2: ATP-binding cassette sub-family G member 2 .

Tumour lymphocyte infiltration. All patients were also evaluated for the presence of CD3 and FOXP3 markers in tumour (Figure 3). The immunosuppressive tumour pattern was defined as tumour samples presenting $\geq 20 \% \mathrm{FOXP}^{+} \mathrm{T}-$ lymphocytes among all infiltrating $\mathrm{CD}^{+} \mathrm{T}$-cells and this cutoff of 20\% represents the lowest quintile (Treg/CD3 >0.195). Figure $3 \mathrm{~A}$ shows the expression of CD3 and FOXP3 in patients with a low and a high Treg/CD3 ratio. The analyses performed on all patients showed that 34 out of 43 woman had a Treg/CD3 ratio $>0.195$ corresponding to $79 \%$ of cases, while 9/43 patients had a low proportion of immunosuppressive infiltrating T-cells (Figure 3B).

In addition, the expression of CD133 was evaluated in those patients with high immunosuppressive tumour pattern. Among the $\mathrm{CD}_{133^{+}}$patients (11/43), 10 of these woman (91\%) had a higher Treg/CD3 ratio and had a significant Treg infiltration compared to those with CD133- samples $\left(91 \% \mathrm{CD} 133^{+}\right.$vs. 50\% CD133-; $\left.p<0.05\right)$. ABCG2 and CD24 did not exhibit any significant correlation with tumour immunosuppression (data not shown).

Survival analyses. The median follow-up of patients was 87.5 months. Overall and progression-free survival were not statistically correlated to the expression of any single marker analyzed. Figure 4 shows the results obtained analysing survival by CD133 and FOXP3 markers.

\section{Discussion}

CSCs have been identified in different solid tumours, including, glioma, melanoma, and prostate, ovarian, lung, colorectal and pancreatic cancer (15-18). This cell population appears to have self-renewal capacity and differentiation potential and inside the tumour it can maintain the stem cell pool, thus sustaining the heterogeneous growth of tumour mass.

In addition, CSCs appear dormant or with slow-cycling states (19), increase resistance to chemo-/radiotherapy (20) and furthermore, CSCs induce angiogenesis and lymphangiogenesis $(21,22)$. Currently, the prognostic implications of CSC presence within tumours are still debated. While different 

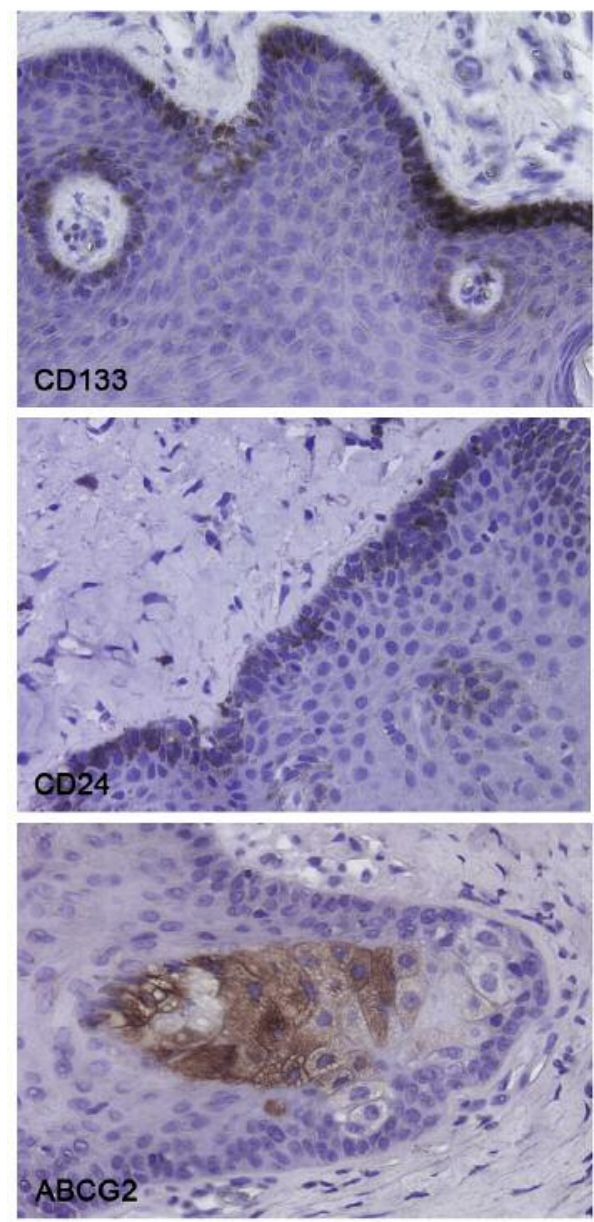

Figure 1. Immunohistochemical analysis of prominin-1 (CD133), CD24 and ATP-binding cassette sub-family $G$ member 2 (ABCG2) in vulvar cancer tissues. Magnification: $\times 20$.

recent studies support the theory that the presence of CSCs within the tumour mass correlates with poor clinical outcome, there are studies that show no such correlation $(23,24)$.

CSCs show phenotypic heterogeneity in the same type of cancer (25), but they can be isolated utilizing specific patterns of surface biomarkers, which allows their identification from non-tumorigenic cells. CSCs can be recognized through the expression of well-characterized cell surface markers, including CD molecules (CD133, CD44, CD24, CD166, etc.), ATP-binding cassette transporters (ABCG2, ABCB5), aldehyde dehydrogenase 1, epithelial cell adhesion molecule, $\mathrm{C}-\mathrm{X}-\mathrm{C}$ chemochine receptor type 4 , and nestin (26).

CD133 is the most investigated CSC marker (27). A very recent meta-analysis carried out in 470 patients affected by different solid tumours treated with chemoradiotherapy assessed the prognostic impact of CD133 expression (28). The analysis pointed out that CD133 expression positively
Pz: 31

CD133

Total positive: 9

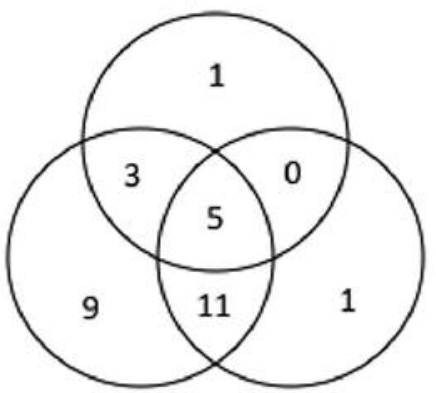

ABCG2

Total positive: 28
Total positive: 17

Figure 2. Venn diagram of positivity for prominin-1 (CD133), ATPbinding cassette sub-family $G$ member 2 (ABCG2) and CD24 in 31 patients with vulvar cancer.

correlated with poorer progression-free and overall survival. In addition, we demonstrated that $\mathrm{CD}_{133^{+}} \mathrm{CSC}$ s isolated from endometrial cancer express the tumour-associated antigen mucin-1 (MUC1). MUC1 make these cells potentially susceptible to immune system attack and contributes to maintaining resistance to cisplatin and paclitaxel (29). Again, CD133 expression was found to be the only independent risk factor in 1,366 patients affected by ovarian cancer with central nervous system metastasis (30).

In the present study, we performed a preliminary evaluation of the immunological and clinical impact of CD133 expressing CSCs in patients with vulvar cancer. We have shown that CD133 expression is present in approximately a quarter of patients suffering from vulvar cancer and that over $90 \%$ of tumour samples expressing this marker exhibited a strong tumour infiltration of Tregs, indicating the presence of a significant immunosuppressive microenvironment. Furthermore, CSCs were more frequently encountered in patients with unfavourable clinical factors such as lymph nodal metastasis, larger tumour diameter and younger age at diagnosis, although no correlation was found with patient survival. To our knowledge, this study is the first experience, in the field of vulvar cancer setting, in which a link between CSCs and immune infiltrate has been found. Despite the limited sample size of 43 patients, a significant correlation between CD133 CSC marker and immunosuppression, evaluated by examining the percentage of Tregs expressing $\mathrm{FOXP}^{+}$, was found. Several hypotheses have been drawn to define this complex interaction highlighting the mutual interaction between Tregs and CSCs. One of these suggests angiogenesis and VEGF levels in tumour microenvironment as an intermediate connection between these 


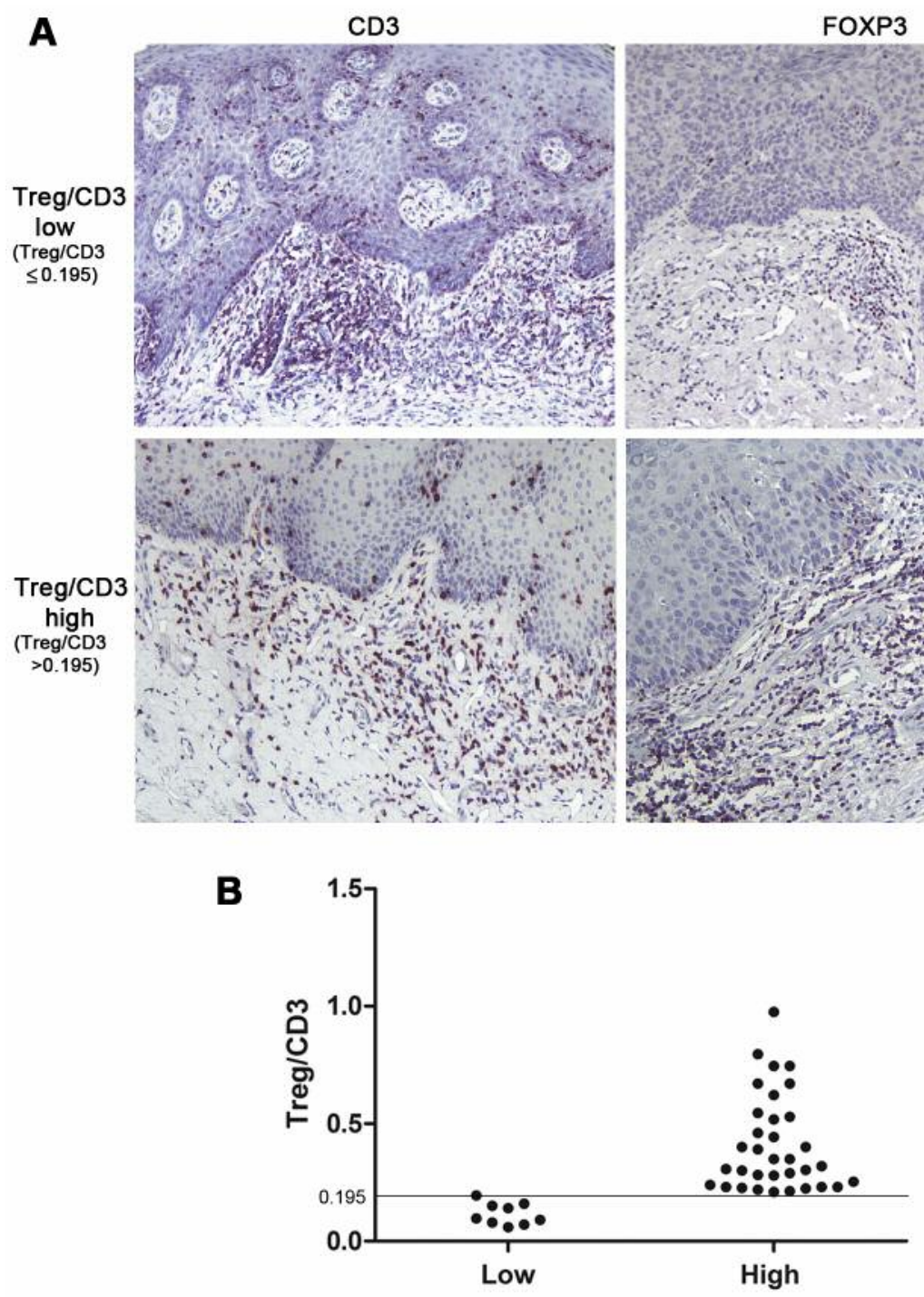

Figure 3. Expression of cluster of differentiation 3 (CD3) and forkhead box protein P3 (FOXP3) according to the regulatory T-cell (Treg)/CD3 ratio in patients affected by vulvar cancer. A: Immunohistochemical analysis of CD3 (left) and FOXP3 (right) markers in vulvar cancer tissues. The images show an example of tumour with a low and a high Treg/CD3 ratio. B: Distribution of cases according to the Treg/CD3 ratio, as low (ratio $\leq 0.195$ ) and high (ratio >0.195). This cut-off value (0.195) represents the lowest quintile.

two cell populations. VEGF signaling is in fact involved in the regulation of CSC stemness and expansion and in the recruitment of Tregs in the tumour microenvironment $(5,6)$. Recently, several reports have demonstrated that the administration of a monoclonal antibody to VEGF (bevacizumab) as an anti-angiogenesis factor, significantly inhibited the proliferation of CSCs and concurrently the level of Tregs in the tumour microenvironment (31-32).

Tregs release VEGF in response to hypoxia and their elimination depletes VEGF production in ovarian cancer (33). In addition, tumour growth factor (TGF)- $\beta$ expressed by Tregs is also involved in this process of increasing the level of VEGF. However, an increase of Tregs is also attributed to the expression of VEGF (32-33). Intriguingly, recent reports demonstrate that interleukin 17-producing Tregs drive cells to become cancer-initiating cells in colorectal cancer (34). Finally, Tregs indirectly interact with CSCs partially driving the differentiation of tumourassociated macrophages that release TGF $\beta$ (35). On the other hand, CSCs also impact on the recruitment, function and status of Tregs. Glioma-associated CSCs induce Tregs, inhibit T-cell proliferation and activation and trigger T-cell 
A
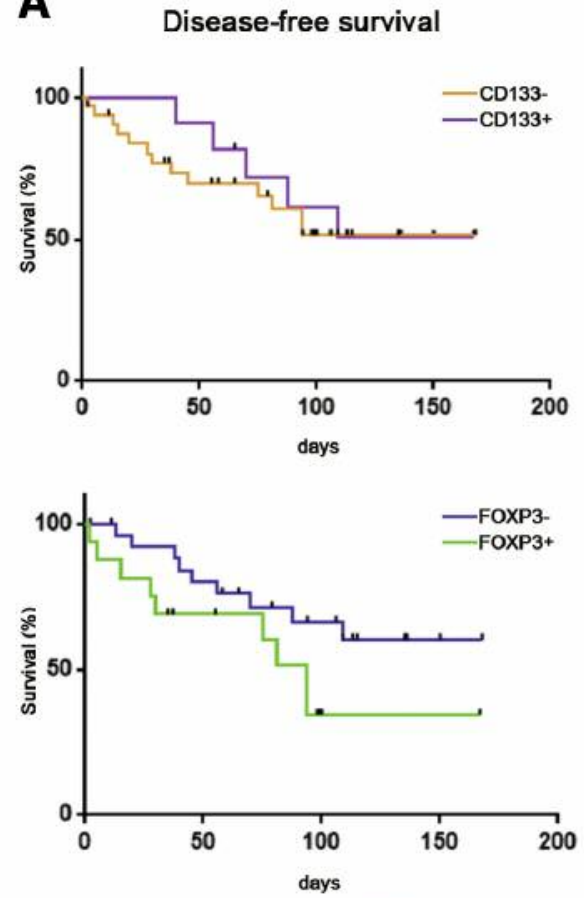

deys

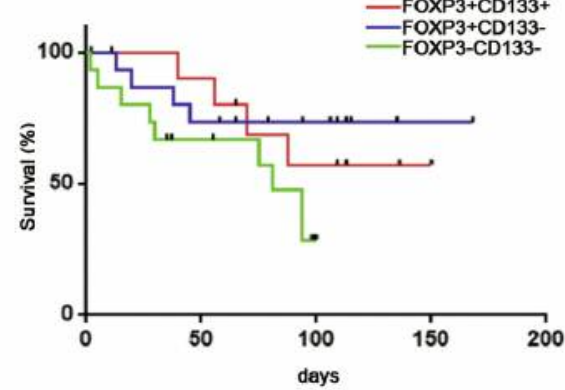

B
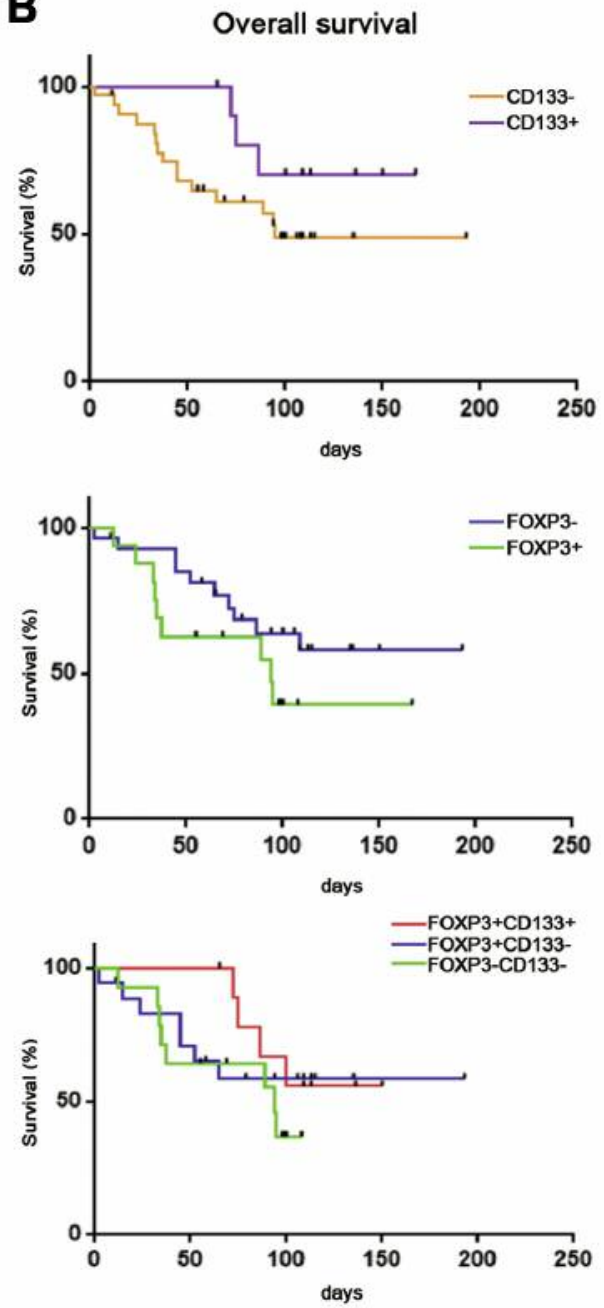

Figure 4. Estimated disease-free (A) and overall (B) survival in patients with vulvar cancer awarding to prominin-1 (CD133) and forkhead box protein P3 (FOXP3) expression.

Table III. Correlation between clinical parameters and expression of cancer stem cell markers.

\begin{tabular}{|c|c|c|c|c|c|c|c|c|c|}
\hline Characteristic & $\begin{array}{c}\mathrm{CD}^{2} 33^{+} \\
\mathrm{n}(\%)\end{array}$ & $\begin{array}{c}\mathrm{CD} 133^{-} \\
\mathrm{n}(\%)\end{array}$ & $p$-Value & $\begin{array}{c}\mathrm{ABCG}^{+}, \\
\mathrm{n}(\%)\end{array}$ & $\begin{array}{c}\mathrm{ABCG}^{-}, \\
\mathrm{n}(\%)\end{array}$ & $p$-Value & $\begin{array}{c}\mathrm{CD} 24^{+}, \\
\mathrm{n}(\%)\end{array}$ & $\begin{array}{c}\mathrm{CD}^{2} 4^{-} \\
\mathrm{n}(\%)\end{array}$ & $p$-Value \\
\hline \multicolumn{10}{|l|}{ Age } \\
\hline$<71$ years & $10 / 43(23.2 \%)$ & $10 / 43(23.2 \%)$ & \multirow[t]{2}{*}{0.001} & $11 / 31(35.5 \%)$ & $2 / 31(6.5 \%)$ & \multirow[t]{2}{*}{0.56} & $8 / 31(25.9 \%)$ & $5 / 31(16.1 \%)$ & \multirow[t]{2}{*}{0.72} \\
\hline$\geq 71$ years & $1 / 43(2.4 \%)$ & $22 / 43(51.2 \%)$ & & $17 / 31(54.8 \%)$ & $1 / 31(3.2 \%)$ & & $9 / 31(29 \%)$ & $9 / 31(29 \%)$ & \\
\hline \multicolumn{10}{|c|}{ Lymph nodal status } \\
\hline $\mathrm{N}(-)$ & $3 / 43(7 \%)$ & $22 / 43(51.2 \%)$ & \multirow[t]{2}{*}{0.03} & $16 / 31(51.6 \%)$ & $3 / 31(9.7 \%)$ & \multirow[t]{2}{*}{0.26} & $10 / 31(32.3 \%)$ & 9/31 (29\%) & \multirow[t]{2}{*}{1.00} \\
\hline $\mathrm{N}(+)$ & $8 / 43(18.6 \%)$ & $10 / 43(23.2 \%)$ & & $12 / 31(38.7 \%)$ & $0 / 31$ & & $7 / 31(22.6 \%)$ & $5 / 31(16.1 \%)$ & \\
\hline \multicolumn{10}{|l|}{ Grading } \\
\hline $\mathrm{G} 1 / \mathrm{G} 2$ & $8 / 43(18.6 \%)$ & $24 / 43(55.8 \%)$ & \multirow[t]{2}{*}{1.00} & $23 / 31(74.2 \%)$ & $3 / 31(9.7 \%)$ & \multirow[t]{2}{*}{1.00} & $15 / 31(48.4 \%)$ & $11 / 31(35.5 \%)$ & \multirow{2}{*}{0.63} \\
\hline G3 & $3 / 43(7 \%)$ & $8 / 43(18.6 \%)$ & & $5 / 31(16.1 \%)$ & $0 / 31$ & & $2 / 31(6.4 \%)$ & $3 / 31(9.7 \%)$ & \\
\hline \multicolumn{10}{|c|}{ Tumor diameter $(\mathrm{cm})$} \\
\hline$<3.2$ & $2 / 43(4.6 \%)$ & $19 / 43(44.2 \%)$ & \multirow[t]{2}{*}{0.03} & $13 / 31(41.9 \%)$ & $2 / 31(6.5 \%)$ & \multirow[t]{2}{*}{0.60} & $6 / 31(19.4 \%)$ & 9/31 (29\%) & \multirow[t]{2}{*}{0.16} \\
\hline$\geq 3.2$ & $9 / 43(21 \%)$ & $13 / 43(30.2 \%)$ & & $15 / 31(48.4 \%)$ & $1 / 31(3.2 \%)$ & & $11 / 31(35.5 \%)$ & $5 / 31(16.1 \%)$ & \\
\hline
\end{tabular}


apoptosis by programmed death-ligand 1 and galectin-3 (36). CSCs also produce TGF $\beta$ that contribute to the induction of Tregs and release the chemokine (C-C motif) ligand 2, which is a potent chemoattractant for Tregs (37).

Vulvar cancer frequently occurs in extremely frail patients. Standard treatment includes radical vulvectomy and bilateral lymphadenectomy. Furthermore, patients with negative prognostic factors are treated with adjuvant radiotherapy. These combined therapeutic strategies frequently determine an impairment of patient mobility due to lymphoedema and nervous and vascular lower limb damage. In the era of personalized medicine, in which new cellular pathways have already been identified as key markers for new successful target therapies (38), increasing evidence is emerging regarding the identification of new biomarkers and their prognostic and predictive role in vulvar cancer (39). If confirmed on larger series, the direct association between CD133, the immunosuppressive pattern and tumour size and lymph node metastases could have several therapeutic implications that could include tailoring lymphadenectomy and introduce new immunological drugs.

\section{Conflicts of Interest}

The Authors declare no conflict of interest in regard to this study.

\section{Acknowledgements}

This work was supported by Sapienza Ateneo 2014 (C26A14WW3A, C.N.), Sapienza Avvio alla Ricerca 2014 (C26N14AHKZ, I.G.Z.; C26N14X3H8, S.C.) and Sapienza Avvio alla Ricerca 2015 (C26N15M7K2, I.R.).

\section{References}

1 Society AC. Cancer Facts \& Figures 2014. Atlanta, GA: American Cancer Society. 2014.

2 Woelber L, Trillsch F, Kock L, Grimm D, Petersen C, Choschzick M, Jaenicke F and Mahner S: Management of patients with vulvar cancer: a perspective review according to tumour stage. Ther Adv Med Oncol 5: 183-192, 2013.

3 Alkatout I, Schubert M, Garbrecht N, Weigel MT, Jonat W, Mundhenke C and Gunther V: Vulvar cancer: epidemiology, clinical presentation, and management options. Int $\mathrm{J}$ Womens Health 7: 305-313, 2015.

4 Reya T, Morrison SJ, Clarke MF and Weissman IL: Stem cells, cancer, and cancer stem cells. Nature 414: 105-111, 2001.

5 Beck B, Driessens G, Goossens S, Youssef KK, Kuchnio A, Caauwe A, Sotiropoulou PA, Loges S, Lapouge G, Candi A, Mascre G, Drogat B, Dekoninck S, Haigh JJ, Carmeliet P and Blanpain C: A vascular niche and a VEGF-Nrp1 loop regulate the initiation and stemness of skin tumours. Nature 478: 399-403, 2011.

6 Gupta S, Joshi K, Wig JD and Arora SK: Intratumoural FOXP3 expression in infiltrating breast carcinoma: Its association with clinicopathologic parameters and angiogenesis. Acta Oncol 46: 792-797, 2007.
7 Wei J, Barr J, Kong LY, Wang Y, Wu A, Sharma AK, Gumin J, Henry V, Colman H, Sawaya R, Lang FF and Heimberger AB: Glioma-associated cancer-initiating cells induce immunosuppression. Clin Cancer Res 16: 461-473, 2010.

8 Ma YC, Yang JY and Yan LN: Relevant markers of cancer stem cells indicate a poor prognosis in hepatocellular carcinoma patients: a meta-analysis. Eur J Gastroenterol Hepatol 25: 10071016, 2013.

9 Hori S, Nomura T and Sakaguchi S: Control of regulatory T cell development by the transcription factor Foxp3. Science 299: 1057-1061, 2003.

10 Sahlberg SH, Spiegelberg D, Glimelius B, Stenerlöw B and Nestor M: Evaluation of cancer stem cell markers CD133, CD44, CD24: association with AKT isoforms and radiation resistance in colon cancer cells. PLoS One 9: e94621, 2014.

11 Weichert W, Denkert C, Burkhardt M, Gansukh T, Bellach J, Altevogt P, Dietel M and Kristiansen G: Cytoplasmic CD24 expression in colorectal cancer independently correlates with shortened patient survival. Clin Cancer Res 11: 6574-6581, 2005.

12 An Y and Ongkeko WM: ABCG2: the key to chemoresistance in cancer stem cells? Expert Opin Drug Metab Toxicol 5: 1529$1542,2009$.

13 Krishnamurthy P, Ross DD, Nakanishi T, Bailey-Dell K, Zhou S, Mercer KE, Sarkadi B, Sorrentino BP and Schuetz JD: The stem cell marker BCRP/ABCG2 enhances hypoxic cell survival through interactions with heme. J Biol Chem 279: 24218-24225, 2004.

14 Ross DD and Nakanishi T: Impact of breast cancer resistance protein on cancer treatment outcomes. Methods Mol Biol 596: 251-290, 2010.

15 Singh SK, Hawkins C, Clarke ID, Squire JA, Bayani J, Hide T, Henkelman RM, Cusimano MD and Dirks PB: Identification of human brain tumour initiating cells. Nature 432: 396-401, 2004.

16 O'Brien CA, Pollett A, Gallinger S and Dick JE: A human colon cancer cell capable of initiating tumour growth in immunodeficient mice. Nature 445: 106-110, 2007.

17 Collins AT, Berry PA, Hyde C, Stower MJ and Maitland NJ: Prospective identification of tumourigenic prostate cancer stem cells. Cancer Res 65: 10946-10951, 2005.

18 Li C, Heidt DG, Dalerba P, Burant CF, Zhang L, Adsay V, Wicha M, Clarke MF and Simeone DM: Identification of pancreatic cancer stem cells. Cancer Res 67: 1030-1037, 2007.

19 Wilson A, Laurenti E, Oser G, van der Wath RC, Blanco-Bose W, Jaworski M, Offner S, Dunant CF, Eshkind L, Bockamp E, Lió P, Macdonald HR and Trumpp A: Hematopoietic stem cells reversibly switch from dormancy to self-renewal during homeostasis and repair. Cell 135: 1118-1129, 2008.

20 Ishii H, Iwatsuki M, Ieta K, Ohta D, Haraguchi N, Mimori K and Mori M: Cancer stem cells and chemoradiation resistance. Cancer Sci 99: 1871-1877, 2008.

21 Ribatti D: Cancer stem cells and tumour angiogenesis. Cancer Lett 321: 13-17, 2012.

22 Yao XH, Ping YF and Bian XW: Contribution of cancer stem cells to tumour vasculogenic mimicry. Protein Cell 2: 266-272, 2011.

23 Yamashita T, Forgues M, Wang W, Kim JW, Ye Q, Jia H, Budhu A, Zanetti KA, Chen Y, Qin LX, Tang ZY and Wang XW: EpCAM and alpha-fetoprotein expression defines novel prognostic subtypes of hepatocellular carcinoma. Cancer Res 68 : 1451-1461, 2008. 
24 Salnikov AV, Kusumawidjaja G, Rausch V, Bruns H, Gross W, Khamidjanov A, Ryschich E, Gebhard MM, Moldenhauer G, Büchler MW, Schemmer P and Herr I: Cancer stem cell marker expression in hepatocellular carcinoma and liver metastases is not sufficient as single prognostic parameter. Cancer Lett 275: 185-193, 2009.

25 Tang DG: Understanding cancer stem cell heterogeneity and plasticity. Cell Res 22: 457-472, 2012.

26 Medema JP: Cancer stem cells: the challenges ahead. Nat Cell Biol 15: 338-344, 2013.

27 Grosse-Gehling P, Fargeas CA, Dittfeld C, Garbe Y, Alison MR, Corbeil D and Kunz-Schughart LA: CD133 as a biomarker for putative cancer stem cells in solid tumours: limitations, problems and challenges. J Pathol 229: 355-378, 2013.

28 Zhai JH, Gu WC, Xu XL, Wu J, Hu XJ and Hou KZ: Prognostic value of CD133 expression in cancer patients treated with chemoradiotherapy: a meta-analysis. Tumor Biol 36: 701-709, 2015.

29 Rutella S, Bonanno G, Procoli A, Mariotti A, Corallo M, Prisco MG, Eramo A, Napoletano C, Gallo D, Perillo A, Nuti M, Pierelli L, Testa U, Scambia G and Ferrandina G: Cells with characteristics of cancer stem/progenitor cells express the CD133 antigen in human endometrial tumours. Clin Cancer Res 15: 4299-4311, 2009.

30 Liu BL, Liu SJ, Baskys A, Cheng H, Han Y, Xie C, Song H, Li $\mathrm{J}$ and Xin XY: Platinum sensitivity and CD133 expression as risk and prognostic predictors of central nervous system metastases in patients with epithelial ovarian cancer. BMC Cancer 14: 829, 2014.

31 Adotevi O, Pere H, Ravel P, Haicheur N, Badoual C, Merillon N, Medioni J, Peyrard S, Roncelin S, Verkarre V, Mejean A, Fridman WH, Oudard S and Tartour E: A decrease of regulatory T-cells correlates with overall survival after sunitinib-based antiangiogenic therapy in metastatic renal cancer patients. J Immunother 33: 991-998, 2010.

32 Li B, Lalani AS, Harding TC, Luan B, Koprivnikar K, Huan Tu G, Prell R, VanRoey MJ, Simmons AD and Jooss K: Vascular endothelial growth factor blockade reduces intratumoral regulatory T-cells and enhances the efficacy of a GM-CSFsecreting cancer immunotherapy. Clin Cancer Res 12: 6808$6816,2006$.
33 Facciabene A, Peng X, Hagemann IS, Balint K, Barchetti A, Wang LP, Gimotty PA, Gilks CB, Lal P, Zhang L and Coukos G: Tumour hypoxia promotes tolerance and angiogenesis via CCL28 and T(reg) cells. Nature 475: 226-230, 2013.

34 Yang S, Wang B, Guan C, Wu B, Cai C, Wang M, Zhang B, Liu $\mathrm{T}$ and Yang P: FOXP3+IL-17+ T-cells promote development of cancer-initiating cells in colorectal cancer. J Leukoc Biol 89: 8591, 2011.

35 Tiemessen MM, Jagger AL, Evans HG, van Herwijnen MJ, John $\mathrm{S}$ and Taams LS: CD4+CD25+FOXP3+ regulatory T-cells induce alternative activation of human monocytes/macrophages. Proc Natl Acad Sci USA 104: 19446-19451, 2007.

36 Wei J, Barr J, Kong LY, Wang Y, Wu A, Sharma AK, Gumin J, Henry V, Colman H, Sawaya R, Lang FF and Heimberger AB: Glioma-associated cancer-initiating cells induce immunosuppression. Clin Cancer Res 16: 461-473, 2010.

37 Wei J, Wu A, Kong LY, Wang Y, Fuller G, Fokt I, Melillo G, Priebe $\mathrm{W}$ and Heimberger AB: Hypoxia potentiates gliomamediated immunosuppression. PLoS One 6: e16195, 2011.

38 Marchetti C, Imperiale L, Gasparri ML, Palaia I, Pignata S, Boni T, Bellati F and Benedetti Panici P: Olaparib, PARP1 inhibitor in ovarian cancer. Expert Opin Investig Drugs 21: 1575-1584, 2012.

39 Bellati F, Napoletano C, Tarquini E, Palaia I, Landi R, Manci N, Spagnoli G, Rughetti A, Panici PB and Nuti M: Cancer testis antigen expression in primary and recurrent vulvar cancer: association with prognostic factors. Eur J Cancer 43: 2621-2627, 2007.
Received May 9, 2016

Revised August 31, 2016

Accepted September 6, 2016 